\title{
The role of culture in influencing sexual and reproductive health of pastoral adolescent girls in Karamoja sub-region in Uganda
}

\author{
Stella Achen ${ }^{*}$ (D), Peter Atekyereza and Charles B. Rwabukwali
}

\begin{abstract}
Sexual and reproductive health (SRH) is vital for general health. However, problems of SRH such as unwanted pregnancies, sexually transmitted infections (STIS), and complications during pregnancy and childbirth among adolescents frequently arise due to risky sexual behaviour. Often, this challenge is linked to socio-cultural issues associated with sexuality which result in disparities in the SRH of adolescent girls. Culture provides rules of sexual conduct between sexes which shape knowledge, beliefs, and practices regarding the sexuality of adolescent girls and influence SRH. However, empirical evidence remains scarce on the role of culture in shaping sexuality which affects the SRH of adolescent girls of pastoral communities. This paper explores the role of culture in shaping the $\mathrm{SRH}$ of adolescent girls in the pastoral communities of Karamoja sub-region in Uganda. Using the ethnographic method, qualitative data from interviews, key informants, and focus groups was obtained from adolescent girls, key informants, and old women in Moroto District to understand the perceptions of sexuality. The authors made audio recordings and took field notes. Atlas.ti 8.4.15 was used to organize the data which was analysed using thematic analysis. The findings showed that the perception of wealth defines sexuality and influences SRH, social support for sexual assault victims promotes SRH, and beliefs and practices of sexuality shape the SRH of adolescent girls.

Promoting a continuous awareness of the harmful cultural practices is vital in attaining SRH among pastoral adolescent girls. Understanding the role of culture in the influence of SRH is important for the effective provision of SRH services.
\end{abstract}

Keywords: Health services, Social support, STIs, Pregnancy, Childbirth, Polygyny, FGC

\section{Introduction}

Sexual and reproductive health (SRH) is a vital component of health that integrates the physical, mental, and social well-being of individuals (WHO 2006). Globally, adolescent girls are at risk of SRH problems (Dehne and Riedner 2005; Shaw 2009). Evidence reveals that problems of SRH, for instance, unwanted pregnancies, STIs, and complications during pregnancy and childbirth among adolescents, frequently arise due to risky sexual

\footnotetext{
* Correspondence: achenstella@yahoo.com

Department of Sociology and Anthropology, Makerere University, P.O Box 7062, Kampala, Uganda
}

\section{Springer Open}

(c) The Author(s). 2021 Open Access This article is licensed under a Creative Commons Attribution 4.0 International License, which permits use, sharing, adaptation, distribution and reproduction in any medium or format, as long as you give appropriate credit to the original author(s) and the source, provide a link to the Creative Commons licence, and indicate if changes were made. The images or other third party material in this article are included in the article's Creative Commons licence, unless indicated otherwise in a credit line to the material. If material is not included in the article's Creative Commons licence and your intended use is not permitted by statutory regulation or exceeds the permitted use, you will need to obtain permission directly from the copyright holder. To view a copy of this licence, visit http://creativecommons.org/licenses/by/4.0/. unprotected sex (Hindin and Adesegun Fatusi 2009; Morris and Rushwan 2015; Serquina-Ramiro 2005). Often, these problems are linked to socio-cultural issues associated with sexuality and result in disparities in SRH of adolescent girls such as early marriages, sexually transmitted infections (STIs) prevalence, and rate of adolescent pregnancies (Starrs et al. 2018).

In Uganda, records indicate that $25 \%$ of adolescents aged 15-19 have begun child-bearing (UBOS and ICF 2017), with $15 \%$ of women being married by the age of 15 and $49 \%$ by the age of 18 (UBOS and ICF 2012). 
However, there are striking variations at regional and local levels (UBOS and ICF 2017). In the Karamoja subregion, 23.6\% of adolescent girls aged 15-19 have begun child-bearing. In this region, $58 \%$ of women are in polygynous unions compared with $25 \%$ nationally. The fertility rates are high, with a total fertility rate (TFR) of 7.9 whereas the national rate is 5.6. Surprisingly, 59\% of women with six or more surviving children in the region want more compared to $20 \%$ of women with six or more surviving children nationally (UBOS and ICF 2018).

The literature on SRH emphasizes access to SRH services for adolescents(Chandra-Mouli et al., 2015; Morris \& Rushwan, 2015; Shoveller et al., 2004). Some scholars have underscored the vitality of access to youthfriendly services such as information and contraception which provide adolescents with the opportunity to make informed choices regarding their reproductive health (Denno et al., 2015; WHO, 2003). However, emphasis on access to these services alone is not sufficient to tackle the challenge of poor SRH among adolescent girls such as STIs, specifically HIV/AIDS, unwanted pregnancies, complications during pregnancy and childbirth, and maternal mortality (Denno et al., 2015; Hindin and Adesegun Fatusi, 2009; Morris and Rushwan, 2015). Addressing such challenges requires multiple approaches; however, an approach that takes into account the cultural practices, beliefs, and attitudes that form the basis of the perceptions of sexuality may be important in promoting SRH among adolescent girls in vulnerable communities such as the pastoralists.

Culture plays a significant role in influencing SRH. Individuals undergo a process of sexual socialization through which they learn the ideologies of femininity and masculinity such as sexual desires, feelings, roles, expressions, and practices of their culture (Parker 2009). Hofstede et al. (2010) note that sexuality is partially predetermined by a culture which is socially learned at the family level, one's neighborhood, and the community. They further note that individuals have patterns of thinking, feeling, and actions acquired in early childhood. These patterns influence sexual conduct that is assumed to essentially be intentional, deliberate, and often shaped within the specific contexts of socially and culturally structured interactions. Arguably, sexual behaviour occurs within cultural settings following the cultural rules that organize it (Parker 2009). Culture shapes knowledge, beliefs, and practices of sexuality which influence the SRH of adolescent girls.

Considering the cultural ideology of sexuality is important because it impacts the way adolescent girls seek SRH services including contraception, maternal and childcare services, prevention and diagnosis of STIs, and use of information services. This is vital as it determines SRH outcomes among vulnerable groups of adolescent girls, particularly those living in traditional settings such as the pastoralists. Further, sexual behaviours such as unprotected sex and multiple sexual partners, often displayed through polygyny, are largely consistent with culture as a result of exposure to perceptions that define sexuality in a society. However, culture provides rules of sexual conduct between sexes such as where, when, and with whom to have sex; these rules equally act as a guide to choosing a potential partner such as knowledge of one's background (Kioli et al. 2012). In African tradition, for example, issues concerning sex are not openly discussed though indirectly talked about by old people (Okechi 2018). This may pose a challenge for adolescents in accessing quality information required to improve their SRH, which has often resulted in SRH problems such as adolescent pregnancies, STIs, unsafe abortion, complications during pregnancy and childbirth, and maternal deaths (Van Der Kwaak et al. 2012).

Different cultures have their standards by which sexual issues are considered and judged as acceptable or deplorable. According to Van Der Kwaak et al. (2012), pastoral communities are characterized by negative SRH outcomes often due to early sexual debut, early marriage, low access to reproductive health services, and the prevalence of potentially harmful traditional practices such as polygyny and female genital circumcision (FGC). Karamoja subregion is not an exception to some of these challenges as it is marked with social inequality and gender discrimination against females (Ayoo et al. 2013). Poor SRH is a common problem among adolescent girls not only in the study communities but in the whole of Karamoja subregion; this results in school dropouts, inability to sufficiently provide for the child, and maternal deaths (UBOS and ICF 2017). In these study communities, SRH choices made by adolescent girls are largely influenced by the perceptions of the community which align with the traditional standards governing sexuality. Understanding these perceptions in a wider socio-cultural context in which SRH takes place is vital in making recommendations that are culturally sensitive and may potentially result in a high uptake of SRH services to improve SRH. Thus, this paper sets out to answer the question 'what is the role of culture in influencing the SRH of pastoral adolescent girls living in Moroto District in Uganda?' In answering this question, the paper sought to explore the socio-cultural perceptions of sexuality associated with SRH of pastoral adolescent girls. The focus of this paper is to explain the role of culture in shaping the SRH of pastoral adolescent girls in the study communities.

\section{The context}

The Karamojong are historically pastoralists as well as agro-pastoralists who traditionally depended on cattle and utilized a transhumant system (Gray 2000). They 
live in traditional settings (Gulliver 1952). Often, cattle are seen as necessary for the family and its propagation through marriage (Muhereza 2010). Females aspire to be fully married with cows as this gives them recognition as members of the husband's family and clan (Stites et al. 2007). This need can influence adolescent girls to find suitors who are wealthy, so as to have a full marriage status. Further, this society is permissive; girls can have sex with men who intend to marry them. Often, this is unprotected sexual intercourse. This is particularly so because of the cultural practice of bride capture where a man has sex with the girl to show his intention of marriage. However, this practice may result in early pregnancy and contracting STIs through unprotected sex by both the female and male. Likewise, the common practice of polygyny that is culturally accepted can lead to STIs for all those in the union. Also, in Karamoja, about $25 \%$ of women are likely to deliver at home. This is risky as complications during childbirth could arise, requiring emergency skilled attendance (UBOS and ICF 2018). It is also important to note that gender inequality exists in Karamoja. Females are burdened with workloads, including providing for their households (Ayoo et al. 2013). This is oppressive to women and could lead to adverse effects especially during pregnancy and childbirth because they do not find enough time to rest and seek required health care. These challenges directly affect adolescent sexual and reproductive health (ASRH).

\section{Study area}

Karamoja sub-region is a semi-arid area and frequently experiences a harsh and unpredictable climate with an annual rainfall of approximately 350 to $1000 \mathrm{~mm}$ (Egeru et al. 2014). The vegetation is parched with hardly any green grass for the cattle during the dry season. The sun is scorching and the wind frequently blows dust making the atmosphere brown. In such a season, the economic activities mainly carried out in this area include young men grazing livestock far away from the homesteads known as manyattas and young women selling charcoal, firewood, and local brew to get money for food to feed their households. In some areas, the people rely on opportunistic cultivation mainly because the little rainfall, climate change, and restrictions on pastoral mobility imposed by the government have resulted in food insecurity. This has led to some level of reliance on food aid in the region and heavy dependence on relief food (Coffey International Development Ltd. 2016; Olum et al. 2017).

\section{Research methods}

\section{Data collection}

The paper is based on a larger ethnographic study design using qualitative methods to obtain data. Data collection took place in Moroto District. The first phase of data collection was conducted between February 2018 and May 2018; the second phase was from November 2018 to February 2019. The sites for data collection were the villages of Nasigiria, Lomuriarangalem, Kadilakenyi, and Kidepo-lobunet, in the sub-counties of Katikekile and Rupa. Different qualitative methods were used to collect the data. Data were collected using five focus group discussions (FGDs) with adolescent girls. In three of the villages, one FGD was conducted in each village. However, in Kidepo-lobunet, two FGDs were conducted because at the time of research there was a traditional marriage ceremony taking place and adolescent girls from different married support groups were present. FGD participants were members of married groups in their communities that supported one another socially and economically. Each FGD was composed of seven to 10 adolescent girl participants. The study targeted married, Karamojong adolescent girls aged 15-19. All other adolescent girls that did not meet these characteristics for inclusion were left out of the study. Married adolescent girls were selected because it is at this stage that girls start to be sexually active, marry, and start childbearing. They were also presumed to have the necessary information required for the study. These adolescent girls were either officially or unofficially married according to what they indicated. Ten key informant interviews (KIIs) were conducted. Key informants (KIs) were community leaders, district officials (technical and political), and leaders or key personnel from non-governmental organizations (NGOs) tackling issues affecting adolescent girls in the Karamoja sub-region. They were selected based on their knowledge, experience, and responsibility concerning issues of adolescent girls in the district. Twelve in-depth interviews (IDIs) were conducted: eight with adolescent girls and four with elderly women. The elderly women participated in the study because their insights and experiences were necessary for understanding the challenges girls encounter at this phase in life. The elderly women included in this study were either leaders or former leaders in their communities and were presumed to be conversant with cultural issues concerning adolescent girls. Their contribution was used to corroborate the information provided by the adolescent girls. Similarly, the adolescent girls selected for IDI were leaders of social groups of adolescent girls or promoters of SRH services such as contraception. The average time spent on each interview was approximately $40 \mathrm{~min}$ for individuals and 90 min for FGDs. Participants who gave their consent to participate in the interviews freely offered their time and the interviews took place in their chosen place of convenience.

Data was collected by a researcher with the help of two research assistants who translated the interviews into Ng'akarimojong, the language spoken by the participants. 
The research assistants were female parish chiefs in Rupa and Katikekile sub-counties who were knowledgeable in the traditions of the Karamojong and often aided NGOs in their work in the sub-counties. The research assistants were trained on what was required during data collection and what kind of data was needed before starting fieldwork. They also played the roles of interpreters and notetakers during interviews. To obtain unbiased information from participants on sensitive topics on sex and sexuality, the researchers used indirect questioning to increase the willingness of participants to provide accurate information. Also, as the research assistants were females, they had often interacted with the participants on different issues that affect them including SRH concerns in their communities. Triangulation of data was done to generate perspectives for constant data comparison. This generated a comprehensive set of findings. Interviews were audiorecorded for those who consented, in addition to the field notes taken. Participant observations were made by the researchers.

\section{Analysis of data}

Data transcription was done by two different people who were fluent in Ng'akarimojong. The transcripts were compared for consistency. Transcription was done to study details. Reading of the transcripts was done to familiarize with the data. Data were organized using the Atlas.ti computer software programme. Thematic analysis was used to analyse data. The researchers analysed verbatim statements from participants to form codes. The codes identified were of interest to the study and used to form categories which were later reduced to themes. Themes were checked for credibility and included perception of wealth and sexuality of adolescent girls, beliefs of sexuality influencing SRH, and influence of polygyny on SRH.

\section{Ethical considerations}

The study protocol was approved by the Research Ethics Committee of the School of Social Sciences, Makerere University. It was registered with the Uganda National Council of Science and Technology (UNCST) under registration number SS 4698. Clearance was also obtained from the local administration in Moroto District after presenting an introductory letter from Makerere University. Verbal and written consent to participate in the study was obtained from all participants after the form was read out to them. However, since all participants were emancipated and indicated as being independent, informed assent was not sought. Efforts were made to ensure privacy and confidentiality for both the data and participants.

\section{The results}

This section presents the results and illustrates the extent that culture determines SRH. This is done by discussing the different themes that emerged from the analysis of the data. The themes included perception of wealth and sexuality of adolescent girls, beliefs of sexuality influencing SRH, and influence of polygyny on SRH.

\section{Perception of wealth and sexuality of adolescent girls}

Different ways were identified in which cattle is seen as wealth. This shaped the sexuality of females and affected the SRH of adolescent girls. A KI stated that:

The people in this place value cattle and look at it as wealth. This makes them to marry off their daughters at a young age which partly explains why adolescent pregnancies are common in our region. (KI, Straight Talk, Moroto)

The data from this theme provided other sub-themes which included bride wealth, forced marriages, and bride capture. Social support networks were another subtheme closely linked with bride capture. The sub-themes on bride wealth and forced marriages were combined because forced marriages were seen to be a result of bride wealth. Each sub-theme is discussed in the subsequent paragraphs.

\section{Bride wealth and sexuality}

In the study, ownership of cattle was associated with prestige as this was traditionally seen as an important source of wealth that every family desires to possess. An older woman aged 59 from Kadilakenyi village remarked, 'for us here...wealth is counted in form of cattle. A family without cattle is considered as poor'. In this regard, parents were reported to marry off their adolescent girls to obtain bride wealth which is paid in terms of cows. Adolescent girls in a FGD in Kidepo-Lobunet Village reported that: 'parents prefer to marry off their daughters to wealthy men regardless of how many wives he already has. Sometimes they do not care to know about the man's HIV sero status'. However, these men were more likely to be older and due to culture are already married to probably more than one wife. It was noted that girls from poorer families were more likely to find themselves in such unions. This risks their SRH and could result in poor outcomes since the man has multiple sexual partners and the girls are under pressure to bear children.

Further, cattle influenced the way the community perceived female sexuality. Females were valued for the potential to generate wealth for the family. It was remarked by one of the old women in the interviews that: 'when 
you have many daughters, you are looked at as rich... especially when they start getting married' (elderly woman aged 63, IDI, Lomuriarangalem Village. This revealed that the sexual unions of adolescent girls were determined by the cows. However, the perception of girls as wealth influenced them to begin courting men at a young age. A KI commented, 'as soon as girls reach puberty, they want to date men; some of them engage in sex with older men for money without consideration of contraception' (KI, Woman Councilor, Local Council 3, Moroto).

In a FGD, adolescent girls revealed how they end up in sexual unions they did not initiate because marriage negotiation and payments of bride wealth take place without their knowledge and input. They narrated:

Parents secretly marry off their daughters by making agreements with old men who have cows to pay for the bride's wealth. Some parents receive part of the bride's wealth without our (girls) knowledge. Then one day the man will come home and they will tell you..., that is your husband. If you refuse him, he waits for you in an isolated place, captures you, and carries you off to his house for sex and you become his wife. (FGD of adolescent girls, Kadilakenyi Village)

The adolescent girls interviewed for this study had either heard or witnessed such incidences in their communities or fallen victims of the same.

In a related sub-theme, the study participants talked about forced marriages. They reported that some adolescent girls in their communities found themselves in forced marriages. However, according to the adolescent participants, a girl may opt out of a forced marriage and elope with a man with whom she shares an emotional attachment. They explained:

A girl can run away with the man she loves and disappears for some years and return with children. If she elopes, she will be cursed by her parents and they can disown her. If the man she elopes with gives them the number of cows they want, they can forgive her and accept the man. (FGD of adolescent girls, Kadilakenyi Village)

Girls who elope were perceived as denying their parents wealth because usually the men they elope with are not in the position to pay the bride wealth as required by the girl's family.

\section{Bride capture}

Another repetitive sub-theme that emerged out of this theme was bride capture. All participants involved in the study admitted that bride capture is a traditional practice by the Karamojong groups in the study area. In some instances, adolescent girls are likely to end up in 'engagement $\operatorname{sex}^{1}$ ' as a result of the bride capture by these men. In an interview, adolescent girls reported that the practice of engagement sex is traditionally accepted in their communities. They explained:

If a man loves a girl or secretly admires her, he will keep monitoring her movements without her knowledge. One day when she is alone in an isolated place, he will capture her and have sexual intercourse (engagement sex) with her to mark her as his wife. (FGD of adolescent girls, Kidepo-Lobunet Village)

The old women in the interviews acknowledged that bride capture is an old tradition practised by the study communities. According to them, this is a traditionally acceptable practice which is seen as normal as long as the man has the intent of marrying the girl. If the boy captures the girl, he carries her to his home and locks her up if she is not willing to be his wife. In one of the interviews with an old woman, she said:

In our days, bride capture was a common practice accompanied by the sexual act. Many of those old women you see around were married as a result of bride capture. This practice is still common especially in village settings. The parents of the boy approach the parents of the girl for negotiations.

It was revealed that bride capture was not punishable by society except in circumstances where the boy failed to meet the requirements of marriage in terms of cows asked by the girl's family. According to study participants, punishment was served by the girl's family in the form of cattle raids. However, due to government intervention against this traditional practice that psychologically affects the girls and harms their SRH, the government and some NGOs are providing support for the victims.

\section{Social support for sexual assault victims}

Social support and medical help is provided to the girls who are victims of sexual or physical assault by men seeking to marry them. At times relatives too physically assault the girls to force them to marry the men. Recovery from the trauma is a process which starts from the time the girl arrives to the shelter of refuge at the police station or at the one provided by some Non-

\footnotetext{
${ }^{1}$ Engagement sex is a cultural practice by Karamojong men, where a man captures a virgin adolescent girl and forces her into sexual intercourse with the intent to marry her.
} 
Governmental Organizations that support girls seeking help. According to a KI:

We work with the hospital to take them through medical examination after counselling to ascertain the extent of damage on their health. Those who have been raped are started on post exposure prophylaxis within 72 hours in case a girl has been infected with the HIV. If it is after 72 hours, we still examine them and put them on some treatment in case HIV infection has occurred. (KI, Department of Child and Family protection Unit, Uganda Police, Moroto District)

The victims of sexual and physical abuse are relieved by the counselling they receive from the place of refuge. The girls come when they have been traumatized and others are at the verge of committing suicide. An interview with a KI revealed that:

Some of these girls come when they want to commit suicide but we counsel them to help them understand the situation they are in, for example, if they have been assaulted and or raped, we tell them that it is not the end of life. If they have been sexually assaulted we take them to the main hospital for further management, and they are checked for HIV status and other infections they could have contracted. (KI, MIFUMI, Moroto District)

Immediately after the girls come to the shelter of refuge, they are given time to come to terms with the ordeal before they are asked to narrate their stories. The girls are offered shelter for about 2 weeks before the reconciliation process with their families can start. However, adolescent girls in remote villages and without any form of education were more likely not to find help after a sexual assault.

\section{Beliefs and practices of sexuality}

Beliefs were perceived to influence sexuality in two different ways; female's sexual relationships and the practice of female genital circumcision (FGC). Each of these sub-themes is discussed in the subsequent paragraphs.

\section{Sexual relationships of females}

Interviews with old women revealed that according to traditional beliefs of sexuality, adolescent girls are not culturally permitted to have sexual relationships with more than one man as this is seen as bringing a curse. An older woman aged 56 in Nasigiria Village explained: 'we have a belief that if an adolescent girl has sex with several men, her uterus will turn and she will not be able to conceive'.
Equally, fidelity was a requirement among married adolescent girls. In a FGD, adolescent girls were asked about infidelity in marriage. The participants perceived it as a shameful thing and a woman who engages in sexual intercourse with several partners was perceived as a disgrace to her husband. They explained:

Married women are not supposed to have sex with men who are not their husbands. If a woman does so, she will be looked at as a prostitute and a disgrace to her husband. She may bring STIs into the marriage. The husband will just abandon her. This behavior is believed to bring a curse in the family. (FGD of adolescent girls, Kidepo-Lobunet Village)

It was reported that a woman who has a man and continues to look for others is a prostitute. Other women in the community will ridicule her for the disgraceful behaviour.

\section{The practice of FGC}

FGC is one of the cultural practices that affect the SRH of adolescent girls in the study communities. Adolescent girls who had undergone this ritual were reported to have challenges at delivery. A KI at Moroto Regional Referral Hospital (MRRH) stated that:

The lady on that bed is 19 years old, she was operated upon. They referred her here from the health center because of complications at birth as a result of FGC. We receive many women especially those who have undergone FGC for emergency services at the time of birth. (Midwife in the maternity ward)

Complications at birth were associated with FGC. These adolescent mothers required emergency skilled assistance in delivery to save not only their lives but of the newborns too.

However, with the complications encountered by women at birth, FGC among the Tepeth ethnic group was linked to the marriageability of girls.

In support of FGC among the Tepeth, control of women's sexuality is reflected as circumcised girls are perceived to easily find partners for marriage. They are believed to be clean and do not emit a foul smell. Also, they are believed to be faithful to their husbands. This makes circumcision to be associated with fidelity.

Furthermore, according to old women participants, FGC promoted self-esteem among those girls who had undergone the ritual. These girls are given unique names that identify them as circumcised. According to an elderly Tepeth woman and community leader aged 60 in Nasigiria Village: 'once a girl is circumcised, she is named Kaparet or Sereteu. A girl ensures that she is 
known by her given name among her peers and the community'. According to participants, girls are proud to possess such names because they portray them as strong, courageous, sexually acceptable, and attractive to men having gone through a traditional ritual that represents their sexuality. They feel society accepts and approves them by applauding their courage.

\section{Polygyny as a sexual practice}

The study further showed that polygyny in the study population was linked to socio-cultural aspects that continue to make it desirable in the community. Polygyny was reported to be associated with wealth and prestige for men. Diverse reasons were given for polygyny, including the need for men to continue having sex when the wife is breastfeeding, infertility of a partner, and to enlarge the family and clan. Nonetheless, some participants were knowledgeable and aware of the consequences of polygyny on their SRH.

I know that polygyny may be associated with STIs but that is my culture. I cannot tell our men to marry only one wife, no one has the power to do that. I just pray that I do not acquire STIs especially HIV/AIDS. (Adolescent girl aged 18, Kadilakenyi Village)

Interviews with adolescent girls revealed that polygyny is a popular and culturally accepted practice in the community. Dialogues with some married adolescent girls in polygynous marriages showed that they do not consider it a problem. An adolescent girl aged 18 years in an IDI in Nasigiria Village observed: 'we have grown up seeing polygyny as a norm in this society. Our mothers are in polygynous marriages...it is a normal thing to us'. Some of the adolescent girls interviewed were in such marriages. In another IDI, one of the adolescent girls aged 19 in Kidepo-Lobunet Village and in a polygynous marriage stated:

Polygyny prevents men from going to look for other women to have sex with, except his wives. I also get to rest from sexual activity when he is with my cowife, a man's demand for sex is continuous...yeah! If I have sex with my husband and I get pregnant before the baby can speak and run, my baby will die because the milk will have been contaminated. Even the people around me will ridicule me.

Also, an old woman in a dialogue revealed that she believed that polygyny was part of their society. According to her, men are proud to have many wives and children. Usually, the women provide the basic needs for themselves and the children they bear. Having a large family in this society is associated with the availability of labour in the home. According to the old woman:

Having a large family is prestigious for the man. He is respected for being able to father and take care of all those children. The wives compete among themselves to produce children for the husband because they believe that the more children one has, the more the love from the husband. (Old woman, aged 62, Kadilakenyi Village)

Polygyny is a way of life for the people in the study communities. A man keeps marrying wives for as long as he has enough cattle for bride wealth. According to study participants, in some circumstances, a man may marry off his daughter and use her bride wealth to marry another woman for himself.

\section{Discussion}

Choice of a marriage partner for adolescent girls was largely dependent on the cultural value placed on cattle. This determined the man she married, and parents had a major influence on who marries their daughter. This kind of marriage arrangement disregards the emotions of the girl. It is a way of informing females that they should not consider the physical appearance of a man when seeking husbands; this shapes their sexuality. However, adolescent girls in such sexual unions are often at risk of contracting STIs due to lack of opportunities to negotiate for safer-sex and the tendency for men to have multiple sexual partners. This can cause problems that spill over to adulthood resulting in ill health for the rest of one's life (Chandra-Mouli et al. 2015). Furthermore, adolescent girls may suffer from complications during pregnancy and childbirth because their bodies are not fully developed to carry babies which could lead to maternal mortality (Morris and Rushwan 2015). Also, adolescent girls were caught up in forced marriages where their parents chose partners for them without their consent. Often this happens because parents will have already used up part of the bride wealth received from these men in bits. This denies adolescent girls the opportunity to express their emotions and experience sexual activity with men they are emotionally attached to. This trains girls to be tolerant of their husbands, regardless of their character.

The practice of widow inheritance influences the view of females as a weaker sex that needs the protection of a male figure at all times. This causes a perception among the girls that their survival depends on men. This equally causes the females to perceive themselves as unable to independently engage in any developmental activity without the help of a male. It puts them in a state of vulnerability. It further exerts male dominance over the 
female, creating a gender inequality in society. However, widow inheritance also implies that the woman continues to engage in sexual intercourse with the relative of the deceased husband. This can have adverse consequences on the SRH of females as it can lead to the spread of STIs such as HIV/AIDS among sexual partners.

The traditional practice of bride capture and engagement sex is intended for marriage. It is a traditionally recognized way of finding wives. The engagement sex after bride capture is a mark on the girl of ownership by the man to show that she is no longer available to any other man for marriage except him. This expression of love is in disregard of the girl's emotional attachment to the man. Engagement sex is at times accompanied by violence as girls try to fight back to set themselves free. Traditionally, it is believed that after engagement sex, the girl feels dirty if she sexually engages with a different man. This feeling, together with the community's perception that the girl now has a husband, compels her to marry the perpetrator, especially if he can pay the bride wealth. This suggests that culturally the females are there for the sexual pleasures of men without much consideration of their own sexual enjoyment.

A similar practice of bride capture has been cited in other parts of Africa and Asia under different circumstances (McKendry-Smith and Jenkins 2016; Nkosi and Buthelezi 2013; Rice 2018; Steiner and Becker 2019). There is substantial evidence that bride capture is a cultural practice among the Zulu and Xhosa communities in South Africa that is not meant to be violent (Nkosi and Buthelezi 2013; Rice 2018). It can be that the girl colludes with the boy, or it occurs without her consent, or the girl's parents are aware (McKendry-Smith and Jenkins 2016; Steiner and Becker 2019). Under any of these circumstances, a Karamojong adolescent girl often ends up in engagement sex because the men ensure to put a mark on the girls as a way of booking them for marriage. Adolescent girls' sexuality and SRH in the study community are shaped by this practice as it is perceived as a standard. As a result of this perception, adolescent girls had no opportunity to have their perpetrators traditionally reprimanded. This practice also promotes promiscuity among men in these communities. This shaped the way females perceived their sexuality. It also hurts the SRH of females as it can influence the way they seek SRH care services when they feel unwell after such sexual encounters. Usually, females are reluctant to go for immediate medical checkup and treatment after such sexual experiences. This could lead to infertility in case she contracted an STI that needs urgent attention.

Further, the traditional beliefs of sexuality shape female sexuality by the influence on emotions of guilt and shame. According to Heinemann et al. (2016), this may affect a girl's self-worth, depending on how she perceives herself in the eyes of others, as she may feel that they are judging her. It trains girls to perceive that women should be chaste to be able to bear children. Since children are valued in the study communities, it is every female's desire to bear children. This belief works in protecting girls from multiple premarital sexual relationships that could lead to adverse SRH outcomes among adolescent girls. Fidelity among married women in the study population was considered a virtue that every female is required to retain.

Beliefs are one way of ensuring that tradition is passed on from one generation to the next. They are a major part of the culture and can be used to control sexuality in society and facilitate membership in a group. Bar-Tal (2000) concretizes this idea by arguing that beliefs are ideas shared by societal members which characterize a society. Beliefs affect the functioning of society and guide societal behaviour. They aid achieving community values and keep cultural norms as the sexuality of girls is largely a reflection of these beliefs. Thus, the wellbeing of adolescents as regards sexuality is a cultural concept. Some cultural values and beliefs can facilitate or hinder SRH (Henok and Takele 2017).

The beliefs about FGC influenced the way girls perceived their sexuality. After circumcision, the girls feel sexually attractive to men; the ritual offers them a sense of pride about their status. It is believed that the ritual transitions girls into womanhood. Equally, the men perceive circumcised girls as mature and ready for sexual intercourse. This suggests that a woman's maturity is associated with circumcision. Also, circumcised women are perceived to be clean and faithful in marriage. The unique names given to girls after circumcision changes their perceptions of sexuality by their physical behaviour and gives them pride by the way they perceive themselves. This impacts the community's view of sexuality and causes the uncircumcised girls to be looked at as young girls and ridiculed by their peers (World Health Organization). FGC in this study is associated with early sexual debut among adolescent girls since from the age of about 9 up to 15 years, after initiation the community perceives them as mature women. This perception impacts on the feelings and behaviour of adolescent girls and causes them to indulge in sexual activity at an early age which could result in STIs and early pregnancies (Van Der Kwaak et al. 2012). However, evidence reveals that FGC possesses both short- and long-term health risks on the SRH of adolescent girls that can be categorized into three areas: gynecological, obstetric, and psychological (Reisel and Creighton 2015; Varol et al. 2014). Nonetheless, the communities practising FGC have argued that it is a cultural right (Caldwell et al. 2000). 
They maintain that it is a process meant to initiate girls to adulthood status and to preserve cultural identity (Rushwan 2013; World Health Organization 2011). This brings contentment among families and girls who have been circumcised, as it is seen as the best intentions towards a young girl by her family (Ruiza et al. 2014).

The sexuality of women in the study communities has been constructed to make them appreciate polygyny. This society has made women believe that a man's sexual needs cannot be satisfied by only one woman. A similar finding is recorded in a study conducted in Ethiopia, Kenya, and Tanzania among pastoralists that revealed that a common belief was held by communities that men need to find sex elsewhere because of postpartum sexual abstinence (Van Der Kwaak et al. 2012). However, in this study, women appreciated polygyny and saw it as an opportunity for them to wean their babies. The belief that the baby will die if the mother gets pregnant before weaning is a sure way of ensuring that women do not indulge in sexual activity for pleasure. It is a logical way of restricting the women's sexual activity to only their husbands since sex outside marriage for women is not condoned in the community. While women in this study did not perceive it as sexual starvation, the findings from a study in Gambia revealed that women in polygynous unions complained of sexual starvation because of restriction of sexual activities to their husbands (Touray 2006).

Nonetheless, polygyny practised by these communities under study can be used as an opportunity for family planning (FP) since it helps couples to space their children. Also, since women in this community practise post-partum sexual abstinence, this can be used as a chance to pass on messages about FP and to educate the community about its benefits (Tilahun et al. 2015; UBOS and ICF 2017). This can equally act as one way of promoting the sexual health of these women as STIs are avoided during that period (Belfield 2009). Furthermore, polygyny is good because the reproductive health of the mother is rejuvenated from the effects of the previous pregnancy before conceiving again; this caters for maternal and child health.

Polygyny is a common practice among most ethnic groups in Uganda. However, the Karamoja sub-region tops the practice (UBOS and ICF 2017). This may be attributed to socio-cultural reasons such as post-partum sexual abstinence which supports its existence. According to Atekyereza (2018), sex is critical in family life as sexual relations are part of society. He, however, cautions that those involved should be responsible because the consequences can be visible for generations. Horton and Hunt (1984) argue that sexual behaviours result from the desire for sexual variety inherent in human beings. They debate that human beings are inclined to seek sex and sex-related activities from more than one individual. The reason that over time such behaviour becomes institutionalized is because the people have been culturally conditioned to behave in such a manner. Polygyny has shaped women's sexuality in this community and conditioned them to view it as a traditionally accepted practice. The constant ways of relieving sexual tension by people in society become the standard behaviour in culture.

\section{Limitations to the study}

This study has possible limitations. These study findings cannot be generalized to all the pastoralists' communities in Uganda because of the differences in settings and cultural standards that may be unique in some particular communities. Also, the methodology used made the study longer, and perhaps, the use of another research design may yield different results.

\section{Conclusion}

$\mathrm{SRH}$ is a vital component of general health. Achieving this requires considering the role of culture in influencing SRH. Culture shaped the SRH of Karamojong pastoral adolescent girls through sexual practices and beliefs. The perception of wealth determined the sexual unions and practices of sexuality which exposed adolescent girls to poor SRH. The cultural sexual practices exposed adolescent girls to sexual assault, STIs, and complications at birth. Interventions seeking to promote SRH among pastoral adolescent girls should first consider the role culture plays in the SRH of such minority and vulnerable groups. Continuous awareness of harmful cultural practices in the community can improve the SRH of pastoral adolescent girls.

\section{Abbreviations}

AIDS: Acquired immunodeficiency syndrome; ASRH: Adolescent sexual and reproductive health; FGD: Focus group discussions; FP: Family planning: FGC: Female genital circumcision; HIV: Human immunodeficiency virus; KIlls: Key informant interviews; SGBV: Sexual and gender-based violence; SRH: Sexual and reproductive health; STIs: Sexually transmitted infections; WHO: World Health Organization

\section{Acknowledgements \\ This study was funded in part by the Swedish International Development Cooperation Agency (Sida) and Makerere University under Sida contribution No.51180060. The authors also wish to recognize the contributions of Dr. Elizabeth Stites, the Research Director of Conflict and Livelihoods, Feinstein International Center and Assistant Research Professor, Fletcher School of Law and Diplomacy and Friedman School of Nutrition Science and Policy, Tufts University. We also recognize the contribution of Mr. Philemon Mukisa Kirunda of the Department of Adult and Community Education, Makerere University.}

\section{Authors' contributions}

Stella Achen: conceptualization, methodology, validation, formal analysis, investigation, writing —original draft, writing — review and editing. Peter Atekyereza: conceptualization, methodology, funding acquisition, supervision, writing-review. Charles B. Rwabukwali: conceptualization, methodology, 
supervision, writing - review. The authors read and approved the final manuscript.

\section{Authors' information}

Not applicable.

\section{Funding}

The Swedish International Development Cooperation Agency (Sida) and Makerere University.

\section{Availability of data and materials}

Not applicable.

\section{Declarations}

\section{Ethics approval and consent to participate}

The study protocol was approved by the Research Ethics Committee in the School of Social Sciences, Makerere University, and registered with the Uganda National Council of Science and Technology (UNCST) under registration number SS 4698. Verbal and written consent was sought from all the participants.

\section{Consent for publication}

Not applicable.

\section{Competing interests}

None

Received: 12 June 2020 Accepted: 7 December 2020

Published online: 24 November 2021

\section{References}

Atekyereza, Peter. 2018. Single Family Lifestyle in Kampala, Uganda: Destiny by Choice or Fate? In Diversification and Reorganization of 'Family' in Uganda and Kenya: A Cross-cultural Analysis, ed. W. Shiino, S. Shiraishi, and C.M. Mpyangu, 3-13. Tokyo: Research Institute for Languages and Cultures of Asia and Africa, Tokyo University of Foreign Studies.

Ayoo, Sandra, Robert Opio, and Oliver T. Kakisa. 2013. Karamoja Situational Analysis: Northern Uganda Women's Empowerment Programme (NUWEP).

Bar-Tal, Dabiel. 2000. Shared Beliefs in a Society: Social Psychological Analysis. Thousand Oaks, California 91320: Sage Publications

Belfield, Toni. 2009. Principles of Contraceptive Care: Choice, Acceptability and Access. Best Practice and Research: Clinical Obstetrics and Gynaecology 23 (2) $177-185$

Caldwell, J., O.L. Orubuloye, and Pat Caldwell. 2000. Female Genital Mutilation: Conditions of Decline. Population Research and Policy Review 19: 233-254.

Chandra-Mouli, Venkatraman, Joar Svanemyr, Avni Amin, Helga Fogstad, Lale Say, Françoise Girard, and Marleen Temmerman. 2015. Twenty Years after International Conference on Population and Development: Where Are We with Adolescent Sexual and Reproductive Health and Rights? Journal of Adolescent Health 56 (1): S1-S6.

Coffey International Development Ltd. 2016. Support for Strategic Review and Planning to Strengthen DFID's Work on Gender Equality and Women and Girls Empowerment in Karamoja Region, Uganda.

Dehne, L. K., Gabriele, R. 2005. Sexually Transmitted Infections Among Adolescents: The Need for Adequate Health Services (M. Berer (ed.)). WHO. http://164.100.130.11:8091/webarsh/ResourcesonARSH/SexuallyTra smittedlnfectionsamongAdolescents.pdf.

Denno, D. M., Hoopes, A. J., Chandra-Mouli, V. 2015. Effective strategies to provide adolescent sexual and reproductive health services and to increase demand and community support. Journal of Adolescent Health, 56(1), S22S41. https://doi.org/10.1016/j.jadohealth.2014.09.012

Egeru, A., Okia C., De Leeuw J. 2014. Trees and Livelihoods in Karamoja, Uganda (Issue December). https://doi.org/10.12774/eod_hd.december2014.egeruaetal.

Gray, Sandra J. 2000. A Memory of Loss: Ecological Politics, Local History and the Evolution of Karimojong Violence. Human Organisation 59 (4): 401-418.

Gulliver, P.H. 1952. The Karamajong Cluster. Journal of the International African Institute 22 (1): 1-22.

Heinemann, Joseph, Sandrine Atallah, and Talli Rosenbaum. 2016. The Impact of Culture and Ethnicity on Sexuality and Sexual Function. Current Sexual Health Reports 8 (3): 144-150.
Henok, A., and E. Takele. 2017. Assessment of Barriers to Reproductive Health Service Utilisation among Bench Maji Zone Pastoralist Communities. Ethiopian Journal of Health Sciences 27 (5): 523-530.

Hindin, J. Michelle, and O. Adesegun Fatusi. 2009. Adolescent Sexual and Reproductive Health in Developing Countries: An Overview of Trends and Interventions. International Perspectives on Sexual and Reproductive Health 35 (2): 58-62.

Hofstede, Geert, Gert Jan Hofstede, and Michael Minkov. 2010. Cultures and Organizations: Software of the Mind. Vol. 10. New York: McGraw Hill.

Horton, P. B., Hunt, C. L. 1984. Sexuality and Sex Roles. In C. Mediate, A. Murphy, \& J. R. Belser (Eds.), Sociology: International Student Edition (6th Edition, pp. 129-153). McGraw-Hill International.

Kioli, Ngunzo, Allan Rosh Were, and Kennedy Onkware. 2012. Traditional Perspectives and Control Mechanisms of Adolescent Sexual Behavior in Kenya. International Journal of Sociology and Anthropology 4 (1): 1-7.

McKendry-Smith, E., Jenkins, T. 2016. Wife Capture. In L. C. Shehan (Ed.), The Wiley-Blackwell Encyclopedia of Family Studies (First Edit, pp. 2054-2056). Wiley-Blackwell. https://doi.org/10.1002/9781119085621.wbefs269.

Morris, Jessica L., and Hamid Rushwan. 2015. Adolescent Sexual and Reproductive Health: The Global Challenges. International Journal of Gynecology \& Obstetrics 131: S40-S52.

Muhereza, F. E. 2010. Drivers of Conflict in Karamoja: An Analysis of Factors Fueling the Countinuing Conflict (Issue October 2010). https://doi.org/10.101 6/j.regsciurbeco.2009.01.001

Nkosi, Makho, and Thabisile Buthelezi. 2013. The Nature and Causes of Bride Abduction Cases in KwaZulu-Natal, South Africa. Stud Tribes Tribals 11 (2): 161-178.

Okechi, O. S. 2018. The Indigenous Concept of Sexuality in African Tradition and Globalization. Global Journal of Reproductive Medicine, 6(1), 001-005. https:// doi.org/10.19080/gjorm.2018.06.555676.

Olum, Solomon, Ipolto Okello-Uma, Gaston A. Tumuhimbise, David Taylor, and Duncan Ongeng. 2017. The Relationship between Cultural Norms and Food Security in the Karamoja Sub-Region of Uganda. Journal of Food and Nutrition Research 5 (6): 427-435.

Parker, Richard. 2009. Sexuality, Culture and Society: Shifting Paradigms in Sexuality Research. Culture, Health and Sexuality 11(3 SPEC. ISS.):251266

Reisel, Dan, and Sarah M. Creighton. 2015. Long Term Health Consequences of Female Genital Mutilation (FGM). Maturitas 80 (1): 48-51.

Rice, Kathleen. 2018. Understanding Ukuthwala: Bride Abduction in the Rural Eastern Cape, South Africa. African Studies 77 (3): 394-411.

Ruiza, Ismael Jiménez, María del Mar Pastor Bravoa, Pilar Almansa Martíneza, and Carmen Ballesteros Meseguera. 2014. Men Facing the Ablation/Female Genital Mutilation (A/FGM): Cultural Factors That Support This Tradition. Social and Behavioral Sciences 132: 631-638.

Rushwan, Hamid. 2013. Female Genital Mutilation: A Tragedy for Women's Reproductive Health. African Journal of Urology 19 (3): 130-133.

Serquina-Ramiro, L. 2005. Physical Intimacy and Sexual Coercion Among Adolescent Intimate Partners in the Philippines. Journal of Adolescent Research 20 (4): 476-496.

Shaw, Dorothy. 2009. Access to Sexual and Reproductive Health for Young People: Bridging the Disconnect between Rights and Reality. International Journal of Gynecology \& Obstetrics 106: 132-136.

Shoveller, Jeean A., Joy L. Johnson, Donald B. Langille, and Terry L. Mitchell. 2004. Socio-Cultural Influences on Young People's Sexual Behavior. Social Science and Medicine 59 (September): 473-487

Starrs, Ann M., Alex C. Ezeh, Gary Barker, Alaka Basu, Jane T. Bertrand, Robert Blum, Awa M. Coll-Seck, Anand Grover, Laura Laski, Monica Roa, Zeba A. Sathar, Lale Say, Gamal I. Serour, Susheela Singh, Karin Stenberg, Marleen Temmerman, Ann Biddlecom, Anna Popinchalk, Cynthia Summers, and Lori S. Ashford. 2018. Accelerate Progress-Sexual and Reproductive Health and Rights for All: Report of the Guttmacher-Lancet Commission. The Lancet 391 (10140): 2642-2692

Steiner, Susan, and Charles M. Becker. 2019. How Marriages Based on Bride Capture Differ: Evidence from Kyrgyzstan. Demographic Research 41 (August): 579-592.

Stites, Elizabeth, D. Akabwai, Dyan Mazurana, and Priscillar Ateyo. 2007. Angering Akujü : Survival and Suffering in Karamoja. A Report on Livelihoods and Human Security in the Karamoja Region of Uganda.

Tilahun, Tizta, Gily Coene, Marleen Temmerman, and Olivier Degomme. 2015. Couple Based Family Planning Education: Changes in Male Involvement and 
Contraceptive Use among Married Couples in Jimma Zone, Ethiopia. BMC Public Health 15 (682): 1-8.

Touray, Isatou. 2006. Sexuality and Women's Sexual Rights in the Gambia. IDS Bulletin 37 (5): 77-83.

UBOS and ICF. 2012. Uganda Demographic and Health Survey 2011. Kampala, Uganda: UBOS and Calverton, Maryland: ICF International Inc.

UBOS and ICF. 2017. Uganda Demographic and Health Survey 2016: Key Indicators Report. Kampala, Uganda: UBOS, and Rockville, Maryland, USA: UBOS and ICF https://www.health.go.ug/sites/default/files/Demographica ndHealthSurvey.pdf.

UBOS and ICF. 2018. Uganda Demographic and Health Survey 2016: Key Indicators Report. Kampala, Uganda: UBOS and Calverton, Maryland: ICF International Inc. https://dhsprogram.com/pubs/pdf/FR333/FR333.pdf

Van Der, K., Anke, G. B., Nduba, J., Van, W., Ferris K., Plummer, D. 2012. Sexual and Reproductive Health of Nomadic Peoples in East Africa: An overview. In A. Van Der Kwaak, G. Baltissen, D. Plummer, K. Ferris, \& J. Nduba (Eds.), Understanding Normadic Realities: Case Studies on Sexual and Reproductive Health and Rights in Eastern Africa. (pp. 11-19). KIT Publishers.

Varol, Nesrin, lan S. Fraser, Cecilia H.M. Ng, Guyo Jaldesa, and John Hall. 2014. Female Genital Mutilation / Cutting - Towards Abandonment of a Harmful Cultural Practice. Australian and New Zealand Journal of Obstetrics and Gynaecology 54: 400-405.

WHO. 2003. Towards Adulthood: Exploring the Sexual and Reproductive Health of Adolescents in South Asia.

WHO. 2006. Defining Sexual Health: Report of technical consultation on sexual health 28-31 January 2002, Geneva. In Sexual health document series (Issue January). https://doi.org/http://www.who.int/reproductivehealth/publications/ sexual_health/defining_sexual_health.pdf

World Health Organization. 2011. An Update on WHO's Work on Female Genital Mutilation (FGM): Progess Report Report.

\section{Publisher's Note}

Springer Nature remains neutral with regard to jurisdictional claims in published maps and institutional affiliations.

\section{Submit your manuscript to a SpringerOpen ${ }^{\circ}$ journal and benefit from:}

- Convenient online submission

- Rigorous peer review

- Open access: articles freely available online

High visibility within the field

- Retaining the copyright to your article

Submit your next manuscript at $\boldsymbol{\nabla}$ springeropen.com 